\title{
PERSEPSI PETERNAK TERHADAP PELAKSANAAN INSEMINASI BUATAN \\ (IB) PADA SAPI POTONG DI KELURAHAN KALAMPANGAN KECAMATAN SABANGAU KOTA PALANGKA RAYA
}

\author{
${ }^{1}$ Mey Anisa Apulina Siboro, ${ }^{2}$ Abdul Mukti, ${ }^{3}$ Yuni Erlina \\ ${ }^{1}$ Alumnus Program Studi Agribisnis Fakultas Pertanian Universitas Palangka Raya \\ ${ }^{2,}{ }^{3}$ Staf Pengajar Program Studi Agribisnis Fakultas Pertanian Univesitas Palangka Raya
}

Email: ahmad.zaki@agb.upr.co.id

\begin{abstract}
ABSTRAK
Tujuan dari penelitian ini adalah: 1). Mendeskripsikan keadaan pelaksanaan kegiatan Inseminasi Buatan (IB) pada Sapi Potong di Kelurahan Kalampangan, Kecamatan Sabangau, Kota Palangka Raya; 2). Menganalisis persepsi peternak terhadap kegiatan Inseminasi Buatan (IB) pada Sapi Potong di Kelurahan Kalampangan, Kecamatan Sabangau, Kota Palangka Raya. Penelitian ini dilaksanakan di Kelurahan Kalampangan pada peternak pelaksana inseminasi buatan (IB) dan peternak non pelaksana inseminasi butaan (IB). Metode yang digunakan untuk menjawab tujuan pertama yaitu menggunakan metode deskriptif melalui wawancara sedangkan untuk menjawab tujuan kedua yaitu dengan metode kuantitatif menggunakan skala likert. Berdasarkan hasil penelitian diketahui pelaksanaan inseminasi buatan pada peternak pelaksana inseminasi buatan dan peternak yang sudah tidak melaksanakan inseminasi buatan lagi di Kelurahan Kalampangan kurang lebih sama, mulai dari pelaksanaan dan pemeliharaan, proses pelaporan birahi, perilaku pakan, jenis gangguan reproduksi ternak yang pernah terjadi, dan biaya inseminasi buatan (IB). Persepsi peternak terhadap inseminasi buatan (IB) dengan indikator pelaksanaan dan pemeliharaan pada Inseminasi Buatan (IB), penggunanaan semen beku pada Inseminasi Buatan (IB), dan perilaku pakan yang dilaksanakan untuk kegiatan Inseminasi Buatan (IB). Respon peternak pelaksana inseminasi buatan (IB) mendapat skor 1659 (Sangat Baik) dan peternak non pelaksana inseminasi buatan (IB) mendapat skor 1281 (Tidak Baik)

Kata Kunci: Persepsi, Kognitif, Afektif, Konatif, Inseminasi Buatan (IB)
\end{abstract}

\begin{abstract}
The objectives of this study are: 1). Describe the state of the implementation of Artificial Insemination (IB) activities on Beef Cows in Kalampangan Village, Sabangau District, Palangka Raya City; 2). Analyzing the perceptions of farmers to Artificial Insemination (IB) activities in Beef Cattle in Kalampangan Village, Sabangau District, Palangka Raya City. This research was conducted in Kalampangan Village on breeders who implement artificial insemination (IB) and breeders who do
\end{abstract}


not implement blind insemination (IB). The method used to answer the first objective is to use a descriptive method through interviews, while to answer the second objective is to use a quantitative method using a Likert scale. Based on the results of the research, it is known that the implementation of artificial insemination in breeders implementing artificial insemination and breeders who are no longer implementing artificial insemination in Kalampangan Village is more or less the same, starting from implementation and maintenance, the process of reporting lust, feed behavior, types of livestock reproductive disorders that have occurred, and artificial insemination cost (IB). Breeder perceptions to artificial insemination (IB) with implementation and maintenance indicators on Artificial Insemination (IB), use of frozen semen in Artificial Insemination (IB), and feed behavior carried out for Artificial Insemination (IB) activities. The response of farmers implementing artificial insemination (IB) got a score of 1659 (Very Good) and farmers who did not implement artificial insemination (IB) got a score of 1281 (Not Good).

Keywords: Perceptions, Cognitive Affective, Conative, Artificial Insemination (IB)

\section{PENDAHULUAN}

Peternakan mempunyai prospek yang baik dimasa depan, karena permintaan akan bahan-bahan yang berasal dari ternak akan terus meningkat seiring dengan pertambahan jumlah penduduk, pendapatan dan kesadaran masyarakat untuk mengkonsumsi pangan bergizi tinggi sebagai pengaruh dari naiknya tingkat pendidikan ratarata penduduk. Pembangunan sektor peternakan merupakan bagian dari pembangunan pertanian yang bertujuan untuk mencapai kondisipeternakan yang tangguh, memiliki kemampuan untuk menyejahterakan para petani peternak, dan kemampuan mendorong pertumbuhan sektor terkait secara keseluruhan. Pembangunan sektor peternakan memiliki nilai strategis dalam memenuhi peningkatan kebutuhan pangan dan kualitas gizi masyarakat (Santoso, 2006).

Pangan merupakan kebutuhan dasar utama manusia yang pemenuhannya merupakan bagian dari hak asasi setiap rakyat Indonesia. Pangan senantiasa harus tersedia secara cukup, aman, bermutu, bergizi, dan beragam dengan harga yang terjangkau daya beli masyarakat, serta tidak bertentangan dengan agama, keyakinan, dan budaya masyarakat. Seiring bertambahnya jumlah penduduk, meningkatnya daya beli masyarakat serta kesadaran akan pentingnya sumber gizi protein hewani maka permintaan konsumsi daging sapi juga terus mengalami peningkatan tiap tahunnya. Oleh sebab itu maka diperlukan upaya meningkatkan produksi daging sapi di Indonesia. Data statistik menunjukkan produksi daging sapi secara nasional mengalami fluktuasi sejak 2015 hingga 2019. Dalam rentang waktu tersebut, tahun 2016 produksi daging sapi di Indonesia mencapai titik tertinggi dengan 518.484 ton. Angka tersebut naik 2,3\% dari tahun sebelumnya. Setelah tahun 2016, produksi daging sapi Indonesia menurun perlahan. Tahun 2017 dan 2018 secara berturutturut Indonesia memproduksi 486.319,7 ton dan 497.971,7 ton. Tahun 2019, berada di titik terendah dengan produksi 490.420,8 ton. Angka tersebut turun 
1,5\% dari tahun 2018 (Badan Pusat Statistik, 2019).

Menghadapi tantangan tersebut, pemerintah menyusun strategi untuk peningkatan produksi daging sapi dalam negeri dengan menggunakan pendekatan yang lebih banyak mengikutsertakan peran aktif masyarakat, sehingga pemerintah mencanangkan Upsus Siwab (Upaya Khusus Sapi Indukan Wajib Bunting). Upsus Siwab (Upaya Khusus Sapi Indukan Wajib Bunting) merupakan program dari kementrian pertanian dalam upaya meningkatkan produktivitas dan populasi ternak sapi di Indonesia dengan tujuan tercapainya swasembada daging sapi di Indonesia. Program ini merupakan keberlanjutan dari program GBIB (Gertak Birahi dan Inseminasi Buatan) sebelumnya, tetapi pada program ini lebih komprehensif dengan lebih mengoptimalkan pelayanan reproduksi kepada sapi-sapi milik peternak.

Kalimantan Tengah sebagai salah satu provinsi yang juga diharapkan dapat berkontribusi dalam pembangunan peternakan terutama untuk jenis ternak sapi potong, dimana Kota Palangka Raya merupakan salah satu sentra ternak sapi potong di Provinsi Kalimantan Tengah. Banyak upaya yang dilakukan pemerintah dalam meningkatkan produksi daging sapi, salah satunya dengan inovasi Inseminasi Buatan dan Kawin Alam melalui Program Upsus Siwab dengan tujuan mempercepat populasi sapi potong dan menghasilkan sapi potong yang unggul. Kecamatan Sabangau memiliki 6 kelurahan yang diantaranya terdapat Kelurahan Kalampangan yang menjadi salah satu kelurahan pelaksana kegiatan Inseminasi Buatan (IB) dalam mendukung program Upsus Siwab.

Kelurahan Kalampangan adalah salah satu kelurahan dimana sebagian besar peternak didaerah tersebut mengadopsi kegiatan Inseminasi Buatan (IB) atau sering dikenal dengan kawin suntik. Percepatan populasi sapi potong dengan Inseminasi Buatan (IB) di Kelurahan Kalampangan sudah berjalan selama 4 tahun (2017-2020). Inseminasi Buatan di Kelurahan Kalampangan berupa kegiatan percepatan populasi sapi dengan menggunakan bantuan jasa manusia atau disebut Inseminator dalam proses pembuahan sapi betina dengan menggunakan semen beku dari sapi pejantan yang sudah tersedia dan terjamin mutunya. Kegiatan ini dimulai dengan pendeteksian birahi pada ternak sapi betina, pelaksanaan IB, pemeriksaan kebuntingan, dan pelaporan kelahiran pedet/anak ternak. Terdapat 9 poknak yang dibentuk di Kelurahan Kalampangan sebagai pelaksana kegiatan inseminasi buatan (IB), dan berdasarkan wawancara terdapat sebanyak 7 poknak yang masih melaksanakan kegiatan Inseminasi Buatan (IB) dan 2 poknak yang tidak melaksanakan Inseminasi Buatan (IB) lagi. Berikut jumlah peternak yang melaksanakan kegiatan Inseminasi Buatan (IB) di Kelurahan Kalampangan per Poknak tahun 2018-2020 dapat dilihat pada Tabel 1.4.

Penerapan kegiatan Inseminasi Buatan (IB) ini ditentukan oleh peternak langsung dan dibantu oleh petugas teknis yang ada, sehingga penting untuk mengetahui bagaimana respon peternak terhadap kegiatan Inseminasi Buatan (IB) tersebut. Dari kondisi tersebut maka penelitian yang berjudul Persepsi Peternak Terhadap Pelaksanaan Inseminasi Buatan (IB) Pada Sapi Potong Di Kelurahan Kalampangan Kecamatan Sabangau Kota Palangka Raya perlu dilakukan. Hal ini menjadi perlu dikaji mengingat penerapan Inseminasi Buatan (IB) telah menjadi salah satu strategi dalam upaya 
peningkatan produksi sapi. Namun, kegiatan Inseminasi Buatan (IB) dalam penerapannya masih mengalami beberapa kendala terutama ada peternak yang masih bergabung dalam poknak pelaksana dan peternak yang tidak lagi tergabung dalam poknak pelaksana inseminasi buatan (IB).

Tabel 1.4. Jumlah Peternak Yang Melaksanakan Inseminasi Buatan (IB) di Kelurahan Kalampangan Per Poknak, 2018-2020

\begin{tabular}{cccccccc}
\hline & Nama & \multicolumn{3}{c}{ Jumlah Peternak } & \multicolumn{3}{c}{$\begin{array}{c}\text { Jumlah Ternak } \\
\text { (Ekor) }\end{array}$} \\
\cline { 3 - 8 } No & $\begin{array}{c}\text { Pokna } \\
\text { k- }\end{array}$ & \multicolumn{3}{c}{ (Org) } & \multicolumn{3}{c}{201} \\
& $\begin{array}{c}\text { Petern } \\
\text { ak }\end{array}$ & $\mathbf{2 0 1}$ & $\mathbf{2 0 1}$ & $\mathbf{2 0 2}$ & $\mathbf{2 0 1}$ & $\mathbf{2 0 1}$ & $\mathbf{2 0 2}$ \\
& & $\mathbf{9}$ & $\mathbf{0}$ & $\mathbf{8}$ & $\mathbf{9}$ & $\mathbf{0}$ \\
\hline
\end{tabular}

\begin{tabular}{|c|c|c|c|c|c|c|c|}
\hline 1. & $\begin{array}{l}\text { Harapa } \\
\text { n Tani- } \\
\text { I }\end{array}$ & 10 & 10 & 4 & 50 & 55 & 20 \\
\hline 2. & Sepaka & & & & & & \\
\hline & $\begin{array}{l}\mathrm{t} \\
\text { Bersa } \\
\left.\mathrm{ma} \mathrm{a}^{*}\right)\end{array}$ & 11 & - & - & 15 & - & - \\
\hline 3. & Ngudi & & & & & & \\
\hline & $\begin{array}{l}\text { Makm } \\
\text { ur }\end{array}$ & 10 & 6 & 9 & 56 & 48 & 34 \\
\hline 4. & $\begin{array}{l}\text { Harapa } \\
\text { n Jaya }\end{array}$ & 14 & 14 & 14 & 83 & 83 & 48 \\
\hline 5. & $\begin{array}{l}\text { Karya } \\
\text { Jaya-II }\end{array}$ & 14 & 14 & 5 & 52 & 67 & 33 \\
\hline 6. & Sumbe & & & & & & \\
\hline & $\begin{array}{l}\mathrm{r} \\
\text { Makm } \\
\text { ur }\end{array}$ & 11 & 11 & 11 & 22 & 34 & 20 \\
\hline 7. & $\begin{array}{l}\text { Jadi } \\
\text { Makm } \\
\text { ur-I*) }\end{array}$ & 10 & - & - & 44 & - & - \\
\hline 8. & $\begin{array}{l}\text { Harapa } \\
\text { n Tani- } \\
\text { II }\end{array}$ & 11 & 6 & 6 & 20 & 30 & 15 \\
\hline 9. & $\begin{array}{l}\text { Karya } \\
\text { Jaya-I }\end{array}$ & 11 & 11 & 8 & 28 & 20 & 30 \\
\hline
\end{tabular}

Sumber: Data Primer, 2020

Sehubungan dengan hal yang sudah diuraikan, maka penelitian ini bertujuan untuk mendeskripsikan keadaan pelaksanaan kegiatan Inseminasi Buatan (IB) pada Sapi Potong di Kelurahan Kalampangan, Kecamatan Sabangau, Kota Palangka Raya dan menganalisis persepsi peternak terhadap kegiatan Inseminasi
Buatan (IB) pada Sapi Potong di Kelurahan Kalampangan, Kecamatan Sabangau, Kota Palangka Raya.

\section{METODE PENELITIAN}

\section{Lokasi dan Waktu Penelitian}

Lokasi penelitian dilakukan di Kelurahan Kalampangan, Kecamatan Sabangau, Kota Palangka Raya. Pemilihan lokasi dilakukan secara sengaja (purposive), dengan pertimbangan bahwa di wilayah Kelurahan Kalampangan Kecamatan Sebangau Kota Palangka Raya, sebagai penghasil populasi ternak sapi terbesar dan juga daerah ini merupakan daerah yang mempunyai peternak sapi potong yang mengadopsi Inseminasi Buatan (IB).

Penelitian ini dilaksanakan dari bulan September 2020 sampai dengan Maret 2021 dengan alokasi meliputi persiapan, penyusunan usulan penelitian, pengumpulan data sampai dengan penyusunan hasil penelitian dan distribusi.

\section{Metode Penentuan Responden}

Responden yang diambil dalam penelitian ini dilakukan dengan menggunakan teknik Propotional Random Sampling dengan cara undian. Secara random diambil 30 peternak sebagai responden dari 9 kelompok ternak yang ada di Kelurahan Kalampangan, dengan pertimbangan jumlah peternak yang tidak setimbang disetiap kelompok ternak. Dimana populasi tersebut terdiri dari 7 poknak yang masih melaksanakan inseminasi buatan (IB) dengan jumlah peternak 57 peternak dan 2 poknak lagi yang sudah tidak melaksanakan inseminasi buatan (IB) dengan jumlah peternak sebanyak 21 peternak. Setiap kelompok ternak pada populasi memiliki kesempatan 
untuk menjadi sampel. Proportional digunakan untuk menentukan jumlah responden pada masing-masing kelompok ternak. Penentuan jumlah responden yang diambil pada setiap kelompok ternak dilakukan dengan menggunakan rumus Propotional, yaitu:

Keterangan:

$$
n_{1}=\frac{N_{1}}{N} \times n
$$

$\mathrm{n}_{1}=$ Jumlah sampel yang diambil menurut stratum

$\mathrm{N}_{1}=$ Jumlah populasi menurut stratum

$\mathrm{N}=$ Jumlah populasi

$\mathrm{n}=$ Jumlah sampel seluruhnya

\section{Metode Pengumpulan Data}

Data yang dikumpulkan dalam penelitian ini adalah data primer dan data sekunder. Data primer diperoleh melalui pengamatan dan wawancara secara langsung pada peternak yang masih melaksanakan Inseminasi Buatan (IB) dan peternak yang tidak melaksanakan Inseminasi Buatan (IB) lagi dengan bantuan daftar pertanyataan (quesioner). Data sekunder diperoleh dari lembaga atau instansi terkait seperti Badan Pusat Statistik, Dinas Pertanian dan Ketahanan Pangan Kota Palangkaraya dan instansi terkait lainnya.

\section{Metode Pengolahan dan Analisis Data}

Analisis data yang digunakan untuk menjawab tujuan penelitian pertama dilakukan analisis deskriptif melalui observasi atau wawancara langsung dengan peternak anggota dan untuk mengetahui tujuan kedua yaitu persepsi peternak terhadap pelaksanaan Inseminasi Buatan (IB) dengan menggunakan skala likert.

Variabel adalah Persepsi Peternak Terhadap Pelaksanaan Inseminasi Buatan (IB). Indikator yang digunakan dalam mengukur respon peternak terhadap pelaksanaan Inseminasi
Buatan (IB) berdasarkan petunjuk pelaksanaan Inseminasi Buatan (IB) pada Pedoman Pelaksanaan Program Upsus Siwab 2019 (Ditjen PKH, 2019), diantaranya dapat dilihat pada Tabel 3.2 berikut.

Tabel 3.2. Definisi operasional, indikator pengukuran dan Klasifikasi Variabel

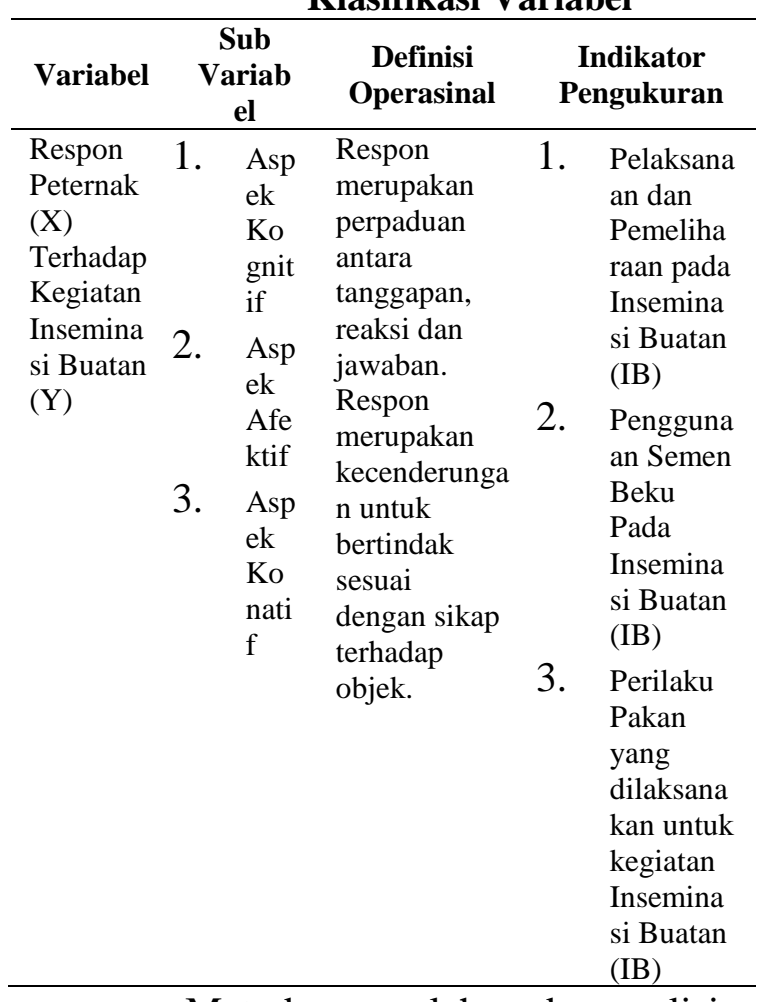
data yaitu dengan menggunakan skala likert. Adapun skala nilai atau skor pada setiap jawaban pertanyaan yaitu:

Sangat Setuju (SS) 5

Sangat Setuju (SS) 5

Setuju (S) $\quad=4$

Setuju (S) $\quad=4$

Ragu-ragu (R) $\quad=3$

Ragu-ragu (R) $\quad=3$

Tidak Setuju (TS) $\quad=2$

Tidak Setuju (S) $=2$

Sangat Tidak Setuju $($ STS $)=1$

Sangat Tidak Setuju (SS) $\quad=1$

Untuk mengukur tingkat respon peternak terhadap Inseminasi Buatan 
(IB) yaitu dengan menggunakan rumus interval kelas dengan rumus:

Dimana

$$
I=\frac{X_{n}-X_{1}}{k}
$$

I : Interval Kelas

$\mathrm{Xn} \quad$ : Nilai Tertinggi

XI : Nilai Terendah

K : Banyaknya kelas atau kategori

Berdasarkan data yang diperoleh dari responden, selanjutnya dapat dilihat untuk penilaian kategori respon peternak terhadap pelaksanaan Inseminasi Buatan (IB) yaitu pelaksanaan dan pemeliharaan pada Inseminasi Buatan (IB), Penggunaan semen beku pada Inseminasi Buatan (IB), dan Perilaku pakan yang dilaksanakan untuk kegiatan Inseminasi Buatan (IB).

\section{HASIL DAN PEMBAHASAN 1. Keadaan Pelaksanaan Inseminasi Buatan (IB) di Kelurahan Kalampangan}

Inseminasi Buatan (IB) merupakan teknik memasukkan mani atau semen ke dalam alat reproduksi ternak betina sehat untuk dapat membuahi sel telur dengan menggunakan alat inseminasi (Dirjen PKH, 2019).

Dari penelitian yang dilakukan pada kelompok ternak pelaksana inseminasi buatan (IB) dan kelompok ternak non pelaksana inseminasi buatan (IB) dapat dilihat dari beberapa aspek yaitu: 1). Pelaksanaan dan pemeliharan; 2). Perilaku Pakan; 3). Kegagalan inseminasi buatan (IB); 4). Biaya; 5). Jumlah pedet yang dihasilkan.

a. Pelaksanaan dan pemeliharaan

Jenis sapi yang dipelihara oleh peternak pelaksana dan non pelaksana rata-rata menggunakan jenis sapi bali, sapi limousin, dan sapi lokal. Pelaksanaan inseminasi buatan (IB) pada responden kelompok ternak pelaksana dan non pelaksana dilakukan peternak dengan cara melaporkan ternaknya melalui alat komunikasi (HP) apabila menunjukkan tanda-tanda birahi. Cara pemeliharaan sapi yang digunakan oleh peternak pelaksana dan peternak non pelaksana adalah dengan membiarkan sapi dikandang terus menerus dan kandang yang dimiliki peternak responden pelaksana ini menggunakan kandang semi permanen. Berdasarkan pengalaman peternak pelakasana dalam beternak, umur ternak sapi yang baik untuk pertama kali dikawinkan yaitu antara 18-24 bulan, sedangkan menurut peternak non pelaksana pada saat umur 20 bulan. Berdasarkan pengalaman peternak pelaksana ternak sapi akan mengalami kebuntingan setelah dilakukan 2 kali perkawinan atau inseminasi, dan lama waktu yang tepat untuk mengawinkan ternak sejak terjadi birahi pertama selama 6-12 jam.Sedangkan pengalaman peternak non pelaksana, ternak sapi akan mengalami kebuntingan setelah dilakukan 3 kali sampai 4 kali perkawinan atau inseminasi, dan lama waktu yang tepat untuk mengawinkan ternak sejak terjadi birahi pertama selama 6-12 jam. Birahi pada ternak sapi pelaksana dan non pelaksana dapat bertahan selama sekitar 12 jam dan jarak antara birahi pertama dengan birahi berikutnya bila tidak terjadi kebuntingan terjadi setelah sekitar 15-21 hari. Jika pada ternak yang sudah dilakukan inseminasi buatan (IB) dan sudah terjadi kelahiran pedet, birahi akan muncul kembali setelah 3645 hari.

b. Perilaku Pakan

Berdasarkan pengalaman peternak pelakasana dalam beternak, dan peternak non pelaksana yang dulunya melaksanakan inseminasi buatan (IB), ternak diberikan tambahan pakan 
hijauan namun rata-rata peternak pelaksana tidak memiliki lahan khusus untuk penggembalaan. Pemberian pakan dilakukan dengan cara mandiri, dimana sumber pakan yang diberikan oleh peternak berasal dari sisa sortasi sayuran yang ditanam oleh peternak dan pemberian pakan kepada ternak dilakukan setiap jam 5 sore oleh masing-masing peternak. Peternak memberikan pakan dengan cara mandiri, dimana sumber pakan yang diberikan oleh peternak berasal dari sisa sortasi sayuran yang ditanam oleh peternak dan pemberian pakan kepada ternak dilakukan setiap jam 5 sore oleh masing-masing peternak.

c. Kegagalan Inseminasi Buatan (IB)

Berdasarkan pengalaman peternak pelakasana dan peternak non pelaksana dalam beternak, ada beberapa gangguan reproduksi yang pernah dialami seperti: 1). Infeksi bakteri pada vagina ternak sapi betina (Endometritis); 2). Distokia yang disebabkan oleh faktor induk dan anak.

\section{d. Biaya}

Berdasarkan pengalaman peternak pelaksana dan non pelaksana dalam beternak di Kelurahan Kalampangan, biaya yang dikenakan untuk setiap pelaksanaan Inseminasi Buatan (IB) peternak mengeluarkan biaya sebesar Rp.100.000 untuk inseminasi buatan jenis sapi Bali dan Rp.300.000 untuk inseminasi buatan jenis sapi Limousin. Dimana biaya ini diberikan oleh peternak kepada petugas Inseminator sekali pembayaran hingga sapi peternak yang di IB mengalami kebuntingan.

e. Jumlah kelahiran

Berdasarkan pengalaman peternak pelakasana dalam beternak, jumlah kelahiran pedet yang dihasilkan 1 induk dapat melahirkan 1 hingga 2 anak ternak atau pedet. Dan berdasarkan hasil wawancara kepada peternak pelaksana, kematian pada anak ternak yang baru lahir pernah terjadi dengan rata-rata jumlah kematian 1 ekor anak ternak. Untuk kematian indukan, rata-rata peternak pelaksana belum pernah mengalami. Sedangkan pada peternak non pelaksana, berdasarkan pengalaman dalam beternak menggunakan inseminasi buatan jumlah kelahiran pedet yang dihasilkan 1 induk dapat melahirkan 1 anak ternak atau pedet. Dan berdasarkan hasil wawancara kepada peternak non pelaksana, kematian pada anak ternak yang baru lahir pernah terjadi dengan rata-rata jumlah kematian 1 ekor anak ternak dan kematian induk yang juga pernah terjadi pada salah satu peternak non pelaksana.

\section{Persepsi Peternak Terhadap Pelaksanaan Inseminasi Buatan (IB) Pada Sapi Potong di Kelurahan Kalampangan}

Persepsi dalam pelaksanaan Inseminasi Buatan (IB) oleh peternak pelaksana dan non pelaksana dapat dilihat dari tingkat respon peternak terhadap adanya teknologi Inseminasi Buatan (IB). Data-data mengenai tingkat respon peternak terhadap pelaksanaan Inseminasi Buatan diperolah dari hasil wawancara maupun kuesioner yang telah diberikan kepada peternak. Respon peternak diukur dari aspek kognitif, aspek afektif, dan konatif.

a. Respon Peternak Terhadap Pelaksanaan Inseminasi Buatan (IB) pada Sub-Variabel Aspek Kognitif

Tabel 5.2 Rekapitulasi Skor Respon Peternak Pelaksana Terhadap Pelaksanaan Inseminasi Buatan (IB) Aspek Kognitif di Kelurahan Kalampangan, Kecamatan Sabangau.

\begin{tabular}{|c|c|c|c|c|c|}
\hline $\begin{array}{l}\text { Sub- } \\
\text { Varia } \\
\text { bel }\end{array}$ & Indikator & $\begin{array}{l}\text { Ite } \\
\text { m }\end{array}$ & $\begin{array}{l}\text { Sk } \\
\text { or }\end{array}$ & $\begin{array}{l}\text { Rat } \\
\text { a- } \\
\text { rata }\end{array}$ & $\begin{array}{l}\text { Kateg } \\
\text { ori }\end{array}$ \\
\hline $\begin{array}{l}\text { Aspek } \\
\text { Kognit } \\
\text { if }\end{array}$ & $\begin{array}{l}\text { pelaksanaa } \\
\text { n dan } \\
\text { pemelihar }\end{array}$ & 3 & 205 & $\begin{array}{c}68,3 \\
3\end{array}$ & Baik \\
\hline
\end{tabular}




\begin{tabular}{|c|c|c|c|c|c|}
\hline & $\begin{array}{l}\text { aan pada } \\
\text { Inseminasi } \\
\text { Buatan } \\
\text { (IB) }\end{array}$ & & & & \\
\hline & $\begin{array}{l}\text { penggunan } \\
\text { aan semen } \\
\text { beku pada } \\
\text { Inseminasi } \\
\text { Buatan } \\
\text { (IB) }\end{array}$ & 2 & 139 & 69,5 & Baik \\
\hline & $\begin{array}{l}\text { perilaku } \\
\text { pakan } \\
\text { yang } \\
\text { dilaksanak } \\
\text { an untuk } \\
\text { kegiatan } \\
\text { Inseminasi } \\
\text { Buatan } \\
\text { (IB) }\end{array}$ & 3 & 206 & $\begin{array}{c}68,6 \\
6\end{array}$ & Baik \\
\hline Total & & 8 & 550 & $\begin{array}{c}91,6 \\
6\end{array}$ & $\begin{array}{c}\text { Sangat } \\
\text { Baik }\end{array}$ \\
\hline
\end{tabular}

Tabel 5.3 Rekapitulasi Skor Respon Peternak Non Pelaksana Terhadap Pelaksanaan Inseminasi Buatan (IB) Aspek Kognitif di Kelurahan Kalampangan, Kecamatan Sabangau

\begin{tabular}{|c|c|c|c|c|c|}
\hline $\begin{array}{l}\text { Sub- } \\
\text { Varia } \\
\text { bel }\end{array}$ & Indikator & $\begin{array}{l}\text { Ite } \\
\text { m }\end{array}$ & $\begin{array}{l}\text { Sk } \\
\text { or }\end{array}$ & $\begin{array}{l}\text { Rat } \\
\text { a- } \\
\text { rata }\end{array}$ & $\begin{array}{l}\text { Kateg } \\
\text { ori }\end{array}$ \\
\hline \multirow{3}{*}{$\begin{array}{l}\text { Aspek } \\
\text { Kognit } \\
\text { if }\end{array}$} & $\begin{array}{l}\text { pelaksanaa } \\
\mathrm{n} \text { dan } \\
\text { pemelihar } \\
\text { aan pada } \\
\text { Inseminasi } \\
\text { Buatan } \\
\text { (IB) }\end{array}$ & 3 & 161 & $\begin{array}{c}53,6 \\
6\end{array}$ & $\begin{array}{c}\text { Ragu- } \\
\text { ragu }\end{array}$ \\
\hline & $\begin{array}{l}\text { penggunan } \\
\text { aan semen } \\
\text { beku pada } \\
\text { Inseminasi } \\
\text { Buatan } \\
\text { (IB) }\end{array}$ & 2 & 106 & 53 & $\begin{array}{c}\text { Ragu- } \\
\text { ragu }\end{array}$ \\
\hline & $\begin{array}{l}\text { perilaku } \\
\text { pakan } \\
\text { yang } \\
\text { dilaksanak } \\
\text { an untuk } \\
\text { kegiatan } \\
\text { Inseminasi } \\
\text { Buatan } \\
\text { (IB) }\end{array}$ & 3 & 157 & $\begin{array}{c}52,3 \\
3\end{array}$ & $\begin{array}{c}\text { Ragu- } \\
\text { ragu }\end{array}$ \\
\hline Total & & 8 & 424 & $\begin{array}{c}70,6 \\
6\end{array}$ & $\begin{array}{l}\text { Tidak } \\
\text { Baik }\end{array}$ \\
\hline
\end{tabular}

Sumber: Data Primer diolah, 2020

b. Respon Peternak Terhadap
Pelaksanaan Inseminasi Buatan (IB) pada Sub-Variabel Aspek Afektif

Tabel 5.4 Rekapitulasi Skor Respon Peternak Pelaksana Terhadap Pelaksanaan Inseminasi Buatan (IB) Aspek Afektif di Kelurahan Kalampangan, Kecamatan Sabangau

\begin{tabular}{|c|c|c|c|c|c|}
\hline $\begin{array}{l}\text { Sub- } \\
\text { Varia } \\
\text { bel }\end{array}$ & Indikator & $\begin{array}{l}\text { Ite } \\
\text { m }\end{array}$ & $\begin{array}{l}\text { Sk } \\
\text { or }\end{array}$ & $\begin{array}{l}\text { Rat } \\
\text { a- } \\
\text { rata }\end{array}$ & $\begin{array}{l}\text { Kateg } \\
\text { ori }\end{array}$ \\
\hline \multirow{3}{*}{$\begin{array}{l}\text { Aspek } \\
\text { Kognit } \\
\text { if }\end{array}$} & $\begin{array}{l}\text { pelaksanaa } \\
\text { n dan } \\
\text { pemelihar } \\
\text { aan pada } \\
\text { Inseminasi } \\
\text { Buatan } \\
\text { (IB) }\end{array}$ & 2 & 141 & 70,5 & Baik \\
\hline & $\begin{array}{l}\text { penggunan } \\
\text { aan semen } \\
\text { beku pada } \\
\text { Inseminasi } \\
\text { Buatan } \\
\text { (IB) }\end{array}$ & 2 & 139 & 69,5 & Baik \\
\hline & $\begin{array}{l}\text { perilaku } \\
\text { pakan } \\
\text { yang } \\
\text { dilaksanak } \\
\text { an untuk } \\
\text { kegiatan } \\
\text { Inseminasi } \\
\text { Buatan } \\
\text { (IB) }\end{array}$ & 3 & 207 & 69 & Baik \\
\hline Total & & 7 & 487 & $\begin{array}{c}92,7 \\
6\end{array}$ & $\begin{array}{c}\text { Sangat } \\
\text { Baik }\end{array}$ \\
\hline
\end{tabular}

Sumber: Data Primer diolah, 2020

Tabel 5.5 Rekapitulasi Skor Respon Peternak Non Pelaksana Terhadap Pelaksanaan Inseminasi Buatan (IB) Aspek Afektif di Kelurahan Kalampangan, Kecamatan Sabangau

\begin{tabular}{|c|c|c|c|c|c|}
\hline $\begin{array}{l}\text { Sub- } \\
\text { Varia } \\
\text { bel }\end{array}$ & Indikator & $\begin{array}{l}\text { Ite } \\
\text { m }\end{array}$ & $\begin{array}{l}\text { Sk } \\
\text { or }\end{array}$ & $\begin{array}{l}\text { Rat } \\
\text { a- } \\
\text { rata }\end{array}$ & $\begin{array}{l}\text { Kateg } \\
\text { ori }\end{array}$ \\
\hline \multirow{3}{*}{$\begin{array}{l}\text { Aspek } \\
\text { Kognit } \\
\text { if }\end{array}$} & $\begin{array}{l}\text { pelaksanaa } \\
\text { n dan } \\
\text { pemelihar } \\
\text { aan pada } \\
\text { Inseminasi } \\
\text { Buatan } \\
\text { (IB) }\end{array}$ & 2 & 105 & 52,5 & $\begin{array}{c}\text { Ragu- } \\
\text { ragu }\end{array}$ \\
\hline & $\begin{array}{l}\text { penggunan } \\
\text { aan semen } \\
\text { beku pada } \\
\text { Inseminasi } \\
\text { Buatan } \\
\text { (IB) }\end{array}$ & 2 & 107 & 53,5 & $\begin{array}{c}\text { Ragu- } \\
\text { ragu }\end{array}$ \\
\hline & perilaku & 3 & 157 & 52,3 & Ragu- \\
\hline
\end{tabular}




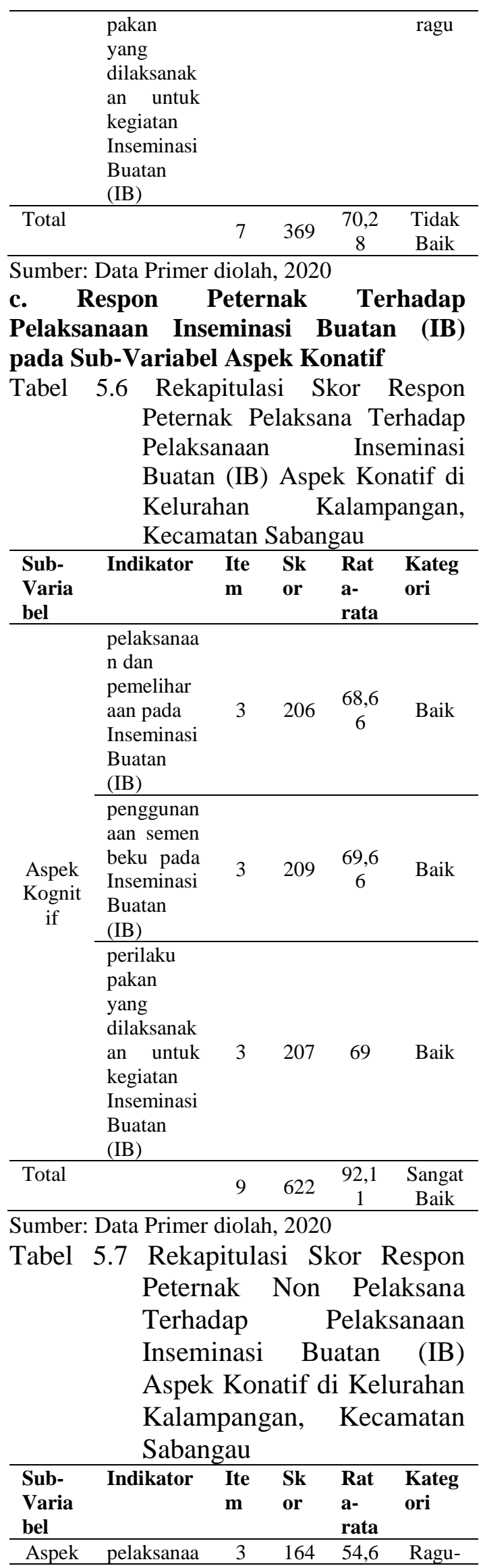

\begin{tabular}{|c|c|c|c|c|c|}
\hline \multirow[t]{3}{*}{$\begin{array}{c}\text { Kognit } \\
\text { if }\end{array}$} & $\begin{array}{l}\mathrm{n} \text { dan } \\
\text { pemelihar } \\
\text { aan pada } \\
\text { Inseminasi } \\
\text { Buatan } \\
\text { (IB) }\end{array}$ & & & 6 & ragu \\
\hline & $\begin{array}{l}\text { penggunan } \\
\text { aan semen } \\
\text { beku pada } \\
\text { Inseminasi } \\
\text { Buatan } \\
\text { (IB) }\end{array}$ & 3 & 163 & $\begin{array}{c}54,3 \\
3\end{array}$ & $\begin{array}{c}\text { Ragu- } \\
\text { ragu }\end{array}$ \\
\hline & $\begin{array}{l}\text { perilaku } \\
\text { pakan } \\
\text { yang } \\
\text { dilaksanak } \\
\text { an untuk } \\
\text { kegiatan } \\
\text { Inseminasi } \\
\text { Buatan } \\
\text { (IB) }\end{array}$ & 3 & 161 & $\begin{array}{c}53,6 \\
6\end{array}$ & $\begin{array}{c}\text { Ragu- } \\
\text { ragu }\end{array}$ \\
\hline Total & & 9 & 488 & $\begin{array}{c}72,2 \\
9\end{array}$ & $\begin{array}{l}\text { Tidak } \\
\text { Baik }\end{array}$ \\
\hline
\end{tabular}

Sumber: Data Primer diolah, 2020

\section{Persepsi Peternak Terhadap} Pelaksanaan Inseminasi Buatan (IB) Secara Keseluruhan di Kelurahan Kalampangan

Berdasarkan analisis skoring (skala likert ) beberapa aspek, yaitu aspek kognitif, aspek afektif dan aspek konatif. Empat aspek tersebut digunakan untuk mengukur tingkat respon peternak pelaksana inseminasi buatan (IB) dan non pelaksana inseminasi buatan (IB) yang berjumlah 30 orang. Rekapitulasi skor respon peternak pelaksana terhadap pelaksanaan inseminasi buatan di Kelurahan Kalampangan Kecamatan Sabagangau dapat dilihat pada Tabel 5.8 Tabel 5.8. Rekapitulasi skor Respon Peternak Pelaksana Inseminasi Buatan (IB) di Kelurahan Kalampangan Kecamatan Sabangau

\begin{tabular}{lcccc}
\hline No & $\begin{array}{c}\text { Tolak Ukur } \\
\text { Penilaian } \\
\text { Respon } \\
\text { Peternak }\end{array}$ & $\begin{array}{c}\text { Total } \\
\text { Skor }\end{array}$ & $\begin{array}{c}\text { Rata- } \\
\text { rata }\end{array}$ & Kategori \\
\hline 1. & $\begin{array}{c}\text { Aspek } \\
\text { Kognitif }\end{array}$ & 550 & 91,66 & $\begin{array}{c}\text { Sangat } \\
\text { Baik }\end{array}$ \\
\hline 2. & $\begin{array}{c}\text { Aspek } \\
\text { Afektif }\end{array}$ & 487 & 92,76 & $\begin{array}{c}\text { Sangat } \\
\text { Baik }\end{array}$ \\
\hline 3. & $\begin{array}{c}\text { Aspek } \\
\text { Konatif }\end{array}$ & 622 & 92,14 & $\begin{array}{c}\text { Sangat } \\
\text { Baik }\end{array}$ \\
\hline Jumlah Skor & 1659 & 92,18 & Sangat \\
\hline
\end{tabular}




\begin{tabular}{|c|c|c|c|c|}
\hline & & & & Baik \\
\hline Sumbe & r: Data Prin & r yang & olah, 2 & \\
\hline Tabel & 5.9. $\mathrm{Re}$ & apitul & i skc & Respon \\
\hline & Pet & nak & Non & elaksana \\
\hline & Ins & ninasi & Buata & (IB) $\mathrm{di}$ \\
\hline & Kel & rahan & $\mathrm{Kal}$ & npangan \\
\hline & $\mathrm{Kec}$ & matar & Saban & \\
\hline No & Tolak Ukur & & & \\
\hline & Penilaian & Total & Rata- & Kategori \\
\hline & Respon & & & \\
\hline & Peternak & & & \\
\hline 1. & Aspek & & & Tidak \\
\hline & Kognitif & 424 & 70,66 & Baik \\
\hline 2. & Aspek & & & Tidak \\
\hline & Afektif & 369 & 70,28 & Baik \\
\hline 3. & Aspek & 488 & 720 & Tidak \\
\hline & Konatif & 488 & 12,29 & Baik \\
\hline Jumlah & Skor & 1281 & 71.07 & Tidak \\
\hline & & & & Baik \\
\hline
\end{tabular}

\section{Kesimpulan}

\section{PENUTUP}

Berdasarkan hasil penelitian dan pembahasan, maka dapat disimpulkan sebagai berikut:

1. Pelaksanaan inseminasi buatan pada peternak pelaksana inseminasi buatan dan peternak yang sudah tidak melaksanakan inseminasi buatan lagi di Kelurahan Kalampangan kurang lebih sama, mulai dari pelaksanaan dan pemeliharaan, proses pelaporan birahi, perilaku pakan, jenis gangguan reproduksi ternak yang pernah terjadi, dan biaya inseminasi buatan (IB). Beberapa hal yang dapat membedakan mengapa peternak tidak lagi menggunakan inseminasi buatan (IB) dikarenakan: a). Tingkat kegagalan inseminasi buatan yang pernah dialami pada ternak membuat peternak memutuskan untuk berhenti melaksanakan; b). Sebagian besar dari peternak non pelaksana mempunyai pekerjaan utama sebagai petani dan beternak merupakan pekerjaan sampingan saja.

2. Persepsi peternak terhadap pelaksanaan Inseminasi Buatan (IB) pada sapi potong di Kelurahan Kalampangan dapat diukur dari aspek kognitif, aspek afektif, dan aspek konatif peternak terhadap pelaksanaan inseminasi buatan (IB) pada sapi potong dengan indikator pelaksanaan dan pemeliharaan pada Inseminasi Buatan (IB), penggunaan semen beku pada Inseminasi Buatan (IB), dan perilaku pakan yang dilaksanakan untuk kegiatan Inseminasi Buatan (IB). Respon peternak pelaksana di Kelurahan Kalampangan terhadap pelaksanaan inseminasi buatan (IB) yaitu mendapat total skor sebesar 1.659 dengan kategori Sangat Baik. Sedangkan Respon peternak non pelaksana di Kelurahan Kalampangan terhadap pelaksanaan inseminasi buatan (IB) yaitu mendapat total skor sebesar 1.281 dengan kategori Tidak Baik:

a). Pada Aspek Kognitif, berdasarkan hasil penelitian lapangan dengan menggunakan bantuan kuesioner yang telah dibagikan, pada indikator pelaksanaan dan pemeliharaan pada kegiatan inseminasi buatan (IB) pada peternak, peternak kurang mengetahui dan menguasai pelaksanaan inseminasi buatan. Respon peternak yang kurang baik dalam menerima hal-hal yang berkaitan dengan pengetahuan bahwa teknik inseminasi buatan (IB) dapat membantu mempercepat proses pelaksanaan perkawinan pada ternak, pengetahuan atau informasi yang kurang pada peternak mengenai bahwa biaya yang digunakan lebih hemat jika dibanding dengan kawin alam, begitupun pada pelaksanaan nya dapat memperkecil atau menurunkan tingkat kecelakaan proses perkawinan. Pada Indikator kedua yaitu penggunaan semen beku terlihat informasi dan pengetahuan 
peternak mengenai bahwa semen beku yang digunakan adalah semen kualitas unggul dan dapat menghasilkan pedet yang unggul juga. Pada indikator ketiga yaitu pemberian pakan pada kegiatan Inseminasi Buatan (IB) terlihat bahwa pengetahuan dan informasi peternak mengenai manfaat pemberian pakan pada inseminasi buatan dapat mempengaruhi jarak kelarihan, mempercepat birahi pada ternak, dan dapat memperbaiki keturunan;

b). Pada Aspek Afektif, dapat dilihat dari skor yang diperoleh bahwa tingkat emosional yang diberikan peternak kurang baik. Peternak non pelaksana inseminasi buatan (IB) memiliki perasaan dan minat yang kurang baik terhadap pelaksanaan inseminasi buatan, hal ini juga menunjukkan bahwa respon peternak dalam menerima hal-hal yang berkaitan dengan inseminasi buatan (IB) kurang baik sehingga peternak tidak mempunyai minat dan tertarik untuk melaksanakan inseminasi buatan. Pada indikator pertama, perasaan dan minat peternak pada saaat merespon pernyataan bahwa pelaksanaan inseminasi buatan (IB) dapat mnghindari terjadinya kawin sedarah kurang baik dan pemeliharaan yang dilakukan pada Inseminasi buatan (IB) lebih maksimal. Pada indikator kedua yaitu penggunaan semen beku sapi penjantan, dimana peternak dapat memilih jenis semen beku yang ingin digunakan, tetapi peternak meresopn kurang baik akan pernyataan tersebut, membuktikan bahwa kurangnya rasa emosional atau ketertarikan untuk melaksanakannya. Pada Indikator ketiga yaitu pemberian pakan yang dilaksanakan pada inseminasi buatan (IB), dimana respon yang dihasilkan melalui pernyataan yang diberikan kepada peternak, peternak adalah kurang baik. Peternak kurang memberi respon yang baik bahwa pakan yang bagus dan jumlah konsumsi yang diberikan berpengaruh terhadap resproduksi yang dapat mengakibatkan kawin berulang;

c). Pada Aspek Konatif, dapat dilihat dari skor yang diperoleh bahwa minat dan ketertarikan berupa perilaku dan tindakan peternak kurang baik. Pada indikator pertama, minat dan ketertarikan peternak non pelaksana pada saat merespon pernyataan bahwa melalui kegiatan inseminasi buatan (IB) dapat memperbaiki kualitas ternak kurang baik dan respon peternak non pelaksana dengan adanya pelaksanaan inseminasi buatan dapat menghindari penularan penyakit pada ternak kurang baik. Pada indikator kedua yaitu penggunaan semen beku sapi penjantan, dimana dengan penggunaan semen beku pada kegiatan inseminasi buatan dapat mempermudah pencarian sapi pejantan jika terdapat birahi pada ternak betina dan penggunaan semen beku pejantan dalam jangka waktu yang lama atau dapat disimpan, tetapi peternak merespon kurang baik akan pernyataan tersebut, membuktikan bahwa kurangnya ketertarikan peternak untuk melakukan hal tersebut kurang baik. Pada indikator ketiga, yaitu pemberian pakan yang dilaksanakan pada inseminasi buatan (IB). Dimana respon yang dihasilkan melalui pernyataan yang diberikan kepada peternak adalah kurang baik. Peternak memberikan respon yang kurang baik terhadap pernyataan bahwa kualitas pakan yang kurang tercukupi akan membuat fungsi 
organ reproduksi ternak terganggu dan pemberian pakan dapat mengoptimalkan proses reproduksi sehingga mengurangi angka kawin berulang.

\section{Saran}

Berdasarkan kesimpulan dari hasil penelitian yang dilakukan di Kelurahan Kalampangan, Kecamatan Sabangau, maka ada beberapa saran yang diajukan, sebagai berikut:

1. Bagi Pemerintah, perlu adanya monitoring dan evaluasi terkait pelaksanaan inseminasi buatan (IB), memberikan penyuluhan informasi mengenai inseminasi buatan (IB), memberikan bantuan lahan khusus untuk penggembalaan ataupun pakan tambahan seperti konsentrat untuk ternak, dan menambah atau mendatangkan petugas ahli bidang inseminasi buatan (IB) pada ternak sapi potong.

2. Bagi Peternak, agar diberikan pelatihan atau sosialisasi mengenai inseminasi buatan (IB) dan penanganan pada ternak yang mengalami gangguan reproduksi agar meningkatkan kemampuan peternak melalui segi pemeliharaan.

\section{DAFTAR PUSTAKA}

Badan Pusat Statistik. 2019. Produksi Daging Sapi menurut Provinsi, 2009-2019. Indonesia

Balai Pengkajian Teknologi Pertanian Aceh. 2017. Laporan Akhir Pendampingan UPSUS SIWAB di Provinsi Aceh. Banda Aceh

Direktorat Jendral Peternakan dan Kesehatan Hewan. 2019. Pedoman Pelaksanaan Upsus Siwab. Jakarta. Kusumawati, E. D dan Leondro, H. 2014. Inseminasi Buatan. Malang Santoso, U. 2006. Manajemen Usaha Ternak Potong. Penebar Swadaya. Jakarta 